\title{
Functional exercise capacity and health-related quality of life in people with asbestos related pleural disease: an observational study
}

\author{
Marita T Dale ${ }^{1,2^{*}}$, Zoe J McKeough ${ }^{1}$, Phillip A Munoz ${ }^{3}$, Peter Corte ${ }^{3}$, Peter TP Bye ${ }^{3,4}$ and Jennifer A Alison ${ }^{1,5}$
}

\begin{abstract}
Background: Functional exercise capacity in people with asbestos related pleural disease (ARPD) is unknown and there are no data on health-related quality of life (HRQoL). The primary aims were to determine whether functional exercise capacity and HRQoL were reduced in people with ARPD. The secondary aim was to determine whether functional exercise capacity was related to peak exercise capacity, HRQoL, physical activity or respiratory function.

Methods: In participants with ARPD, exercise capacity was measured by the six-minute walk test (6MWT) and incremental cycle test (ICT); HRQoL by the St George's Respiratory Questionnaire and physical activity by an activity monitor worn for one week. Participants also underwent lung function testing.

Results: 25 males completed the study with a mean (SD) age of 71 (6) years, FVC 82 (19)\% predicted, FEV / /FVC 66 (11)\%, TLC 80 (19)\% predicted and DLCO 59 (13)\% predicted. Participants had reduced exercise capacity demonstrated by six-minute walk distance (6MWD) of $76(11) \%$ predicted and peak work rate of 71 (21)\% predicted. HRQoL was also reduced. The 6MWD correlated with peak work rate ( $r=0.58, p=0.002)$, St George's Respiratory Questionnaire Total score $(r=-0.57, p=0.003)$, metabolic equivalents from the activity monitor $(r=0.45, p<0.05)$, and FVC \% predicted $(r=0.52, p<0.01)$.

Conclusions: People with ARPD have reduced exercise capacity and HRQoL. The 6MWT may be a useful surrogate measure of peak exercise capacity and physical activity levels in the absence of cardiopulmonary exercise testing and activity monitors.
\end{abstract}

Trial registration: ANZCTR12608000147381

Keywords: 6-minute walk test, Asbestos related diffuse pleural thickening, Exercise capacity, Physical activity, Quality of life

\section{Background}

Asbestos related pleural disease (ARPD) is a worldwide problem with non-malignant pleural disease a common manifestation of asbestos exposure. Despite tighter regulations in the use of asbestos in many developed countries, the legacy of asbestos exposure remains and the incidence of asbestos-related pleural abnormalities continues to rise.

\footnotetext{
* Correspondence: maritad@uni.sydney.edu.au

'Discipline of Physiotherapy (Rm0166) Faculty of Health Sciences, The University of Sydney, 75 East St Lidcombe, Sydney, NSW 2141, Australia ${ }^{2}$ Physiotherapy Department, St Vincent's Hospital, Sydney, NSW, Australia Full list of author information is available at the end of the article
}

Asbestos related pleural disease may result in pleural fibrosis [1]. Despite being recognized as a separate entity to pulmonary fibrosis [2], ARPD remains poorly investigated and understood. The ensuing symptoms, such as shortness of breath on exertion [3,4] are similar to other chronic respiratory diseases and may cause considerable functional impairment to the individual. Previous studies have demonstrated abnormal responses or reductions in peak exercise capacity during cardiopulmonary exercise testing [5-7] in people with ARPD. However, no studies have investigated the effects of ARPD on functional exercise capacity.

The six-minute walk test (6MWT) is a measure of functional exercise capacity widely used in the assessment

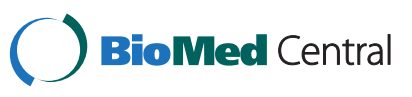


of lung diseases including chronic obstructive pulmonary disease (COPD) [8]. Evidence is growing for the value of the 6MWT in evaluating functional exercise capacity in interstitial lung diseases [9] yet functional exercise capacity in people with ARPD is unknown.

The effects of ARPD on health-related quality of life (HRQoL) have not previously been investigated. Chronic respiratory diseases are frequently associated with decrements in HRQoL [10]. Furthermore, there are no data on the effects of ARPD on levels of physical activity. Levels of physical activity in other lung diseases, such as COPD, have been linked to health outcomes and HRQoL [11,12].

The primary aims of this study were to determine whether functional exercise capacity and HRQoL were reduced in people with ARPD. The secondary aim was to determine whether functional exercise capacity was related to peak exercise capacity, HRQoL, physical activity or respiratory function.

\section{Methods \\ Subjects}

This observational study was conducted at Royal Prince Alfred Hospital, Sydney, Australia from November 2008 - August 2010. Participants were recruited through the Workers' Compensation Dust Diseases Board (DDB) of New South Wales, respiratory physicians, support groups, workers' unions and newsletters for returned servicemen.

People were eligible to participate if they had a diagnosis of ARPD, defined as asbestos-related diffuse pleural thickening and/ or rounded atelectasis. Diagnosis had been established by the participant's respiratory physician or the DDB Medical Authority, a panel of three respiratory physicians with specialist knowledge in occupational lung disease. The diagnostic process at the DDB has previously been described, and includes radiological investigation, lung function testing, clinical examination by a thoracic physician and a lifetime occupational history [13]. Computerised tomography (CT) scans had been conducted on all participants prior to study commencement.

People were excluded from the study if they had mesothelioma; discrete parietal pleural plaques as their only manifestation of dust exposure; cardiovascular, neurological or orthopaedic conditions limiting exercise performance; were on long term oxygen therapy; could not understand English; or had participated in pulmonary rehabilitation within the last 12 months.

The study was approved by the Human Research Ethics Committee of Sydney South West Area Health Service. All participants gave written informed consent.

\section{Pulmonary function tests}

Participants performed pulmonary function tests of spirometry, lung volumes (body plethysmography) and single breath diffusing capacity for carbon monoxide $\left(D_{\mathrm{L}} \mathrm{CO}\right)$ (SensorMedics, Yorba Linda, Ca, USA). Tests were performed according to American Thoracic Society (ATS) guidelines and results expressed as a percentage of predicted values [14-16]. Maximal voluntary ventilation $(\mathrm{MVV})$ was calculated as forced expiratory volume in one second $\left(\mathrm{FEV}_{1}\right)$ multiplied by 40 [17]. Forced vital capacity (FVC) and $\mathrm{D}_{\mathrm{L}} \mathrm{CO}$ were the pulmonary function values used in the correlation analyses.

\section{Exercise testing}

Participants performed two 6MWTs (6MWT 1 and 6MWT 2) according to ATS guidelines [18] on a 32metre oval track with tests separated by a minimum of 30 minutes. Throughout both tests standardised instructions and encouragement were given. Each minute pulse rate (PR) and oxygen saturation $\left(\mathrm{SpO}_{2}\right)$ were measured $\left(\right.$ Radical $^{\mathrm{TM}}$, Masimo Corporation, Irvine, USA) and dyspnoea and rate of perceived exertion (RPE) scores ranging from 0-10 (0 was 'nothing at all' and 10 was 'maximal') were recorded $[19,20]$. The better $6 \mathrm{MWT}$ was used for analysis.

On a second day of testing, participants performed a symptom-limited incremental cycle test (ICT) to peak work capacity on an electromagnetically-braked cycle ergometer (Lode BV, Groningen, The Netherlands). Following two minutes of rest and one minute of unloaded cycling, work rate was increased every minute by a predetermined amount, from 5 to $20 \mathrm{~W} \cdot \mathrm{min}^{-1}$ according to the participant's self-reported exercise capacity and disease severity so that the test was approximately $10 \mathrm{~min}$ utes duration [21]. Breath-by-breath values for oxygen uptake $\left(\mathrm{VO}_{2}\right)$ and carbon dioxide output $\left(\mathrm{VCO}_{2}\right)$ were obtained (Vmax Encore, SensorMedics, Yorba Linda, USA). Volume and gas calibration were performed prior to each test. Pulse rate and $\mathrm{SpO}_{2}$ were simultaneously measured and dyspnoea and RPE scores were recorded each minute and at peak work rate. The test was ceased when the participant reached symptom-limited maximum. Results of the 6MWT and ICT were compared to predicted normal values [22,23].

\section{Health-related quality of life (HRQoL)}

Participants completed the St George's Respiratory Questionnaire (SGRQ) [24]. A priori, the 'Activity' domain and 'Total' score from the SGRQ were identified to examine against measures of exercise capacity.

\section{Physical activity}

Participants wore an activity monitor (SenseWear Pro3 Armband, BodyMedia, Pittsburgh, PA, USA) for one- 
week when not attending exercise testing. Participants were instructed to wear the armband continuously, removing it only when showering or swimming. The activity monitor, worn on the right triceps, incorporated a biaxial accelerometer and sensors for skin temperature, heat flux, and galvanic skin resistance. Mean data on steps per day, the daily metabolic equivalents (METs) and energy expenditure were recorded. A minimum compliance of three days of wear with a daily compliance level of $85 \%$ was specified for increased measurement accuracy [25]. If this level of compliance was not achieved, the data or day was excluded from analysis.

\section{Statistical analysis}

Statistical analysis was performed on PASW-Windows (release 18.0; PASW, Chicago, IL, USA). Data are expressed as mean (SD) or ( $95 \% \mathrm{CI})$. A paired-sample $t$ test was used to compare the distance walked in 6MWT 1 and 6MWT 2, and to compare dyspnoea, PR and RPE achieved in the better 6MWT with those from the ICT. Relationships between variables were examined using Pearson's correlation coefficients. The level of significance was set at a $p$-value of $<0.05$.

\section{Results}

Subjects

Twenty-eight male participants were assessed with 25 included in the study. The reasons for non-inclusion of three participants were pain affecting exercise performance (one), neurological impairment (one) and a significant degree of emphysema (one). Mean anthropometric data and pulmonary function are shown in Table 1.

\section{Exercise capacity}

Participants demonstrated reduced functional exercise capacity measured by the $6 \mathrm{MWT}$ when compared to predicted values [22] (Table 2). Participants also demonstrated reduced peak work capacity. The subjective reasons for ceasing the ICT were dyspnoea in eight participants, leg fatigue in ten participants and combined dyspnoea and leg fatigue in seven participants.

\section{Health-related quality of life}

Participants demonstrated reduced levels of HRQoL across all domains of the SGRQ. Mean data are shown in Table 2.

\section{Repeatability of the six-minute walk test}

There was a significant mean difference between 6MWT 1 and 6MWT 2 of 13 metres (95\% CI: 6 to 21) $(p<0.001)$ with $80 \%$ of participants walking further on 6MWT 2 .
Table 1 Demographic data, pulmonary function and smoking history

\begin{tabular}{lc}
\hline & $\mathbf{n}=\mathbf{2 5}$ mean $(\mathbf{S D})$ \\
\hline Age, yr & $71(6)$ \\
Height, cm & $174(5)$ \\
Weight, kg & $84(12)$ \\
$\mathrm{BMI}, \mathrm{kg} / \mathrm{m}^{2}$ & $28(3)$ \\
$\mathrm{FVC}, \%$ pred & $82(19)$ \\
$\mathrm{FEV}_{1}, \%$ pred & $74(20)$ \\
$\mathrm{FEV}_{1} / \mathrm{FVC} \%$ & $66(11)$ \\
$\mathrm{TLC}, \%$ pred & $80(19)$ \\
$\mathrm{FRC}, \%$ pred & $80(23)$ \\
$\mathrm{RV}, \%$ pred & $78(29)$ \\
$\mathrm{D}_{\mathrm{L}} \mathrm{CO}, \%$ pred & $59(13)$ \\
KCO, \% pred & $84(18)$ \\
Smoking, pack year & $12(15)$ \\
Never smoked (n) & 6 \\
\hline
\end{tabular}

$n=$ number; $S D=$ standard deviation; $y r=$ year; $\mathrm{cm}=$ centimetre; $\mathrm{kg}=$ kilogram; $B M I=$ body mass index; $\mathrm{m}=$ metre; $F V C=$ forced vital capacity; \% pred $=$ percentage of predicted value; $F E V_{1}=$ forced expiratory volume in one second; $T L C=$ total lung capacity; $F R C=$ functional residual capacity; $R V=$ residual volume; $D_{L} C O=$ diffusing capacity for carbon monoxide; $K C O=$ carbon monoxide transfer coefficient.

\section{Responses during the better 6MWT}

In the better $6 \mathrm{MWT}, 44 \%$ of participants desaturated by $\geq 4 \%$. There was a significantly greater desaturation during the 6MWT compared to the ICT, mean difference 3\% (95\% CI: 1 to 4$),(p<0.001)$. The PR, RPE and dyspnoea responses at the end of the 6MWT were significantly lower than at the end of the ICT (Table 3). The minute-by-minute $\mathrm{SpO}_{2}$ and $\mathrm{PR}$ responses during the 6MWT are shown in Figures 1 and 2.

\section{Relationships between functional and peak exercise capacity}

There were significant positive correlations between 6MWD and peak work rate, $\mathrm{r}=0.58(p=0.002)$ and between 6MWD and $\mathrm{VO}_{2}$ peak $(\mathrm{ml} / \mathrm{kg} / \mathrm{min}), \quad \mathrm{r}=0.53$ $(p=0.006)$.

\section{Physical activity}

The activity monitor data was unavailable for two participants who did not wear it for the minimum three days due to skin irritation. Among remaining participants, the activity monitor was worn for a mean (SD) of 6 (1) days with a mean compliance of 98 (1)\%. Physical activity data are presented in Table 2.

Relationships of exercise capacity to lung function, physical activity and health-related quality of life The 6MWD was significantly correlated with pulmonary function, physical activity and HRQoL (Table 4). 
Table 2 Exercise test results for the 6MWT and the ICT, health-related quality of life and physical activity data

\begin{tabular}{|c|c|}
\hline & mean (SD) \\
\hline 6MWT & $n=25$ \\
\hline $6 \mathrm{MWD}, \mathrm{m}$ & $486(68)$ \\
\hline $6 \mathrm{MWD}, \%$ pred & $76(11)$ \\
\hline Resting $\mathrm{SpO}_{2}, \%$ & $97(1)$ \\
\hline Desaturation, \% & $4(3)$ \\
\hline Peak PR, \% pred* & $67(11)$ \\
\hline Dyspnoea at test end & $2(2)$ \\
\hline RPE at test end & $1(2)$ \\
\hline ICT & $n=25$ \\
\hline Work rate peak $_{1}$ W & $114(36)$ \\
\hline Work rate $_{\text {peak, }} \%$ pred & $71(21)$ \\
\hline $\mathrm{VO}_{2}$ peak, $\%$ pred & $83(22)$ \\
\hline $\mathrm{VE}, \mathrm{L} / \mathrm{min}$ & $54(14)$ \\
\hline VE/MW & $63(16)$ \\
\hline Resting $\mathrm{SpO}_{2}, \%$ & $99(1)$ \\
\hline Desaturation, \% & $1(2)$ \\
\hline PR, \% pred & $82(13)$ \\
\hline Dyspnoea at peak & $4(2)$ \\
\hline RPE at peak & $5(2)$ \\
\hline HRQoL & $\mathbf{n}=\mathbf{2 5}$ \\
\hline SGRQ Symptoms & $29(21)$ \\
\hline SGRQ Activity & $34(22)$ \\
\hline SGRQ Impacts & $15(14)$ \\
\hline SGRQ Total & $23(15)$ \\
\hline Physical activity & $n=23$ \\
\hline Average daily steps & 9072 (3186) \\
\hline Average daily METs & $1.3(0.2)$ \\
\hline Average daily EE, cal & $2630(459)$ \\
\hline
\end{tabular}

$S D=$ standard deviation; $6 M W T=$ six-minute walk test; $n=$ number; $6 M W D=$ six-minute walk distance; $m=$ metre; $\%$ pred = percentage of predicted value; $\mathrm{SpO}_{2}=$ oxygen saturation; $P R=$ pulse rate; $R P E=$ rate of perceived exertion; $I C T=$ incremental cycle test; $W=$ watts; $\mathrm{VO}_{2}$ peak $\%$ pred $=$ percent of predicted normal maximal oxygen uptake; $V E$

$=$ minute ventilation; $M V V=$ maximal voluntary ventilation; $H R Q O L=$ healthrelated quality of life; $S G R Q=$ St George's Respiratory Questionnaire; METS

$=$ metabolic equivalent; $E E=$ energy expenditure; $c a l=$ calorie.

* Predicted PR $=220-$ age.

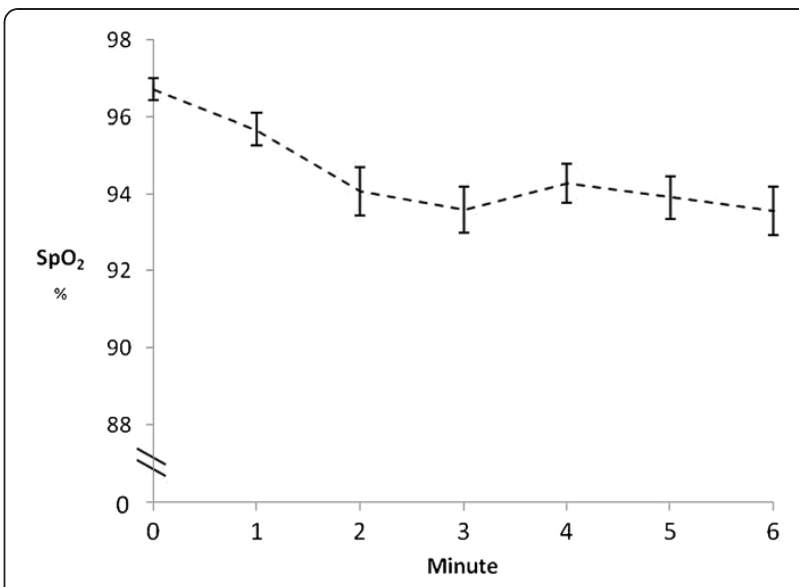

Figure $1 \mathrm{SpO}_{2}$ response during the $6 \mathrm{MWT}$. $\mathrm{SpO}_{2}=$ oxygen

saturation; Error bars = Standard error.

\section{Discussion}

This study examined the effects of ARPD on functional exercise capacity and HRQoL. The main findings were people with ARPD had reduced functional exercise capacity and HRQoL, despite only having pleural involvement. In addition, this study showed significant relationships of functional exercise capacity to peak exercise capacity, physical activity and HRQoL in people with ARPD. The relationships demonstrated that a lower 6MWD was significantly associated with a lower peak work rate, level of physical activity and HRQoL. Such findings have not been previously demonstrated.

Functional exercise capacity and peak exercise capacity were reduced compared to predicted values. At peak exercise, the limiting symptom was leg fatigue in $40 \%$ of participants and dyspnoea in 32\% of participants. Leg fatigue at exercise levels below predicted peak may indicate peripheral deconditioning [26] whereas dyspnoea as the limiting symptom may be attributable to decreased chest wall compliance caused by diffuse pleural thickening [5]. These findings differ from a study in people with idiopathic pulmonary fibrosis (IPF), which reported that $35 \%$ of participants stopped exercise due to leg fatigue and $65 \%$ due to dyspnoea [27]. This difference is likely due to greater disease severity in the IPF group compared to the people with ARPD, but also may be attributable to the slightly older age of our participants. The higher prevalence of leg fatigue may be associated with skeletal muscle changes attributable to aging [28],

Table 3 Mean difference in end exercise PR, dyspnoea and RPE between ICT and 6MWT

\begin{tabular}{|c|c|c|c|c|}
\hline Variable & ICT mean $(\mathrm{SD})$ & 6MWT mean (SD) & Mean difference $(95 \% \mathrm{Cl})$ & $p$ \\
\hline $\mathrm{PR}, \mathrm{b} / \mathrm{min}$ & $122(19)$ & $100(15)$ & 21 (14 to 28) & $<0.001$ \\
\hline Dyspnoea, score & $4(2)$ & $2(2)$ & 3 (2 to 4) & $<0.001$ \\
\hline RPE, score & $5(2)$ & $1(2)$ & 4 (3 to 5) & $<0.001$ \\
\hline
\end{tabular}

$I C T=$ incremental cycle test; $6 M W T=$ six-minute walk test; $S D=$ standard deviation; $C I=$ confidence interval; $P R=$ pulse rate; $b /$ min $=$ beats per minute; $R P E=$ rate of perceived exertion. 


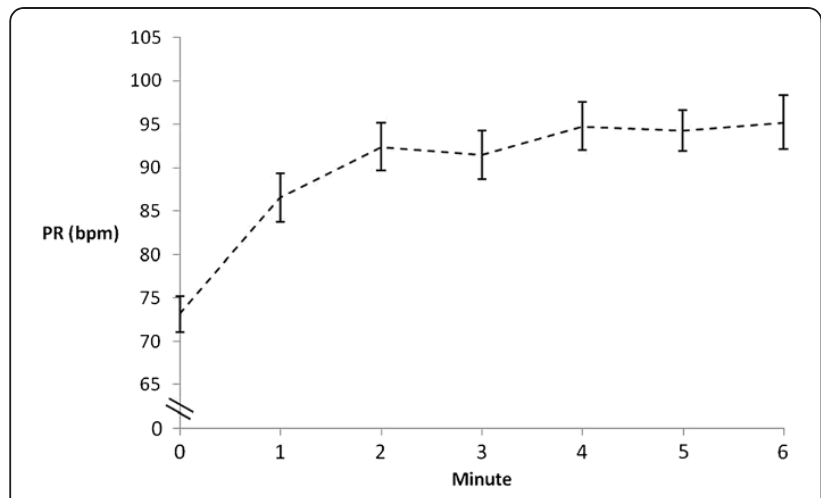

Figure 2 Pulse rate response during the $6 \mathrm{MWT}$. $\mathrm{PR}=$ pulse rate; $\mathrm{bpm}=$ beats per minute; Error bars $=$ Standard error.

resulting in greater peripheral deconditioning and earlier onset of leg fatigue.

Health-related quality of life was reduced in people with ARPD as measured by the SGRQ domains. Despite these reductions, people with ARPD had higher levels of HRQoL than reported in people with IPF [29] and COPD [30]. To our knowledge, this is the first study to demonstrate that people with ARPD experience reductions in HRQoL.

In people with ARPD we have demonstrated a moderate relationship between 6MWD and peak work rate, although weaker than relationships in COPD $(r=0.63$, $p<0.002 ; \mathrm{r}=0.75, \mathrm{p}<0.001))[31,32]$. We have also demonstrated a moderate relationship between 6MWD and $\mathrm{VO}_{2}$ peak $(\mathrm{ml} / \mathrm{kg} / \mathrm{min})$, although weaker than in endstage lung diseases $(r=0.73, p<0.001)$ [33]. This is likely due to the lesser disease severity in our participants. Despite this, the relationship between 6MWD and peak exercise capacity suggests that the 6MWT may be a useful surrogate measure of peak exercise capacity in people

\begin{tabular}{lcc} 
Table $\mathbf{4}$ Relationships between $\mathbf{6 M W D}$ or peak work rate \\
and HRQoL scores, pulmonary function tests and \\
measures of physical activity (r-values) \\
\hline Variable & \multicolumn{2}{c}{ ARPD $\mathbf{n}=\mathbf{2 5}$} \\
\hline FVC, \% pred & $0.52^{\dagger}$ & Peak work rate \\
D CO, \% pred & $0.50^{\ddagger}$ & $0.59^{\dagger}$ \\
Daily steps & 0.38 & $0.64^{*}$ \\
Daily METs & $0.45^{\ddagger}$ & 0.24 \\
Daily energy expenditure & 0.06 & 0.22 \\
SGRQ Total & $-0.57^{\dagger}$ & 0.25 \\
SGRQ Activity & $-0.50^{\ddagger}$ & $-0.71^{*}$ \\
\hline
\end{tabular}

${ }^{*} p<0.001,{ }^{\dagger} p<0.01,{ }^{\ddagger} p<0.05$.

$A R P D=$ asbestos related pleural disease; $n=$ number; $6 M W D=$ six-minute walk distance; $F V C=$ forced vital capacity; \% pred = percentage of predicted value; $D_{L} C O=$ diffusing capacity for carbon monoxide; $M E T s=$ metabolic equivalent $S G R Q=$ St George's Respiratory Questionnaire. with ARPD when cardiopulmonary exercise testing is unavailable.

The 6MWT correlated moderately with the SGRQ Total score and the SGRQ Activity domain score, similar to relationships reported in COPD and interstitial lung disease [24,29]. This suggests the impact of ARPD on HRQoL may be reflected by the SGRQ, a questionnaire originally designed for people with COPD.

Physical activity differs from exercise capacity. Higher levels of daily physical activity have health benefits for people with COPD [34] or coronary artery disease [35]. Conversely, reduced physical activity is related to increased morbidity and mortality in COPD [11]. In this study, the 6MWD correlated more strongly with daily METs than did peak work rate, demonstrating the 6MWD may better reflect daily physical activity than a peak exercise test. This is likely the consequence of daily activities being performed at sub-maximal levels of intensity, rather than maximal levels of intensity [18]. In the absence of activity monitors in the clinical setting, the 6MWT may be a useful surrogate measure of physical activity.

There was a significant increase in distance walked between the first and second $6 \mathrm{MWT}$ of 13 metres or $3 \%$, a smaller increase than reported in COPD [36] and interstitial lung disease [9]. In COPD, two 6MWTs are recommended to obtain an accurate measure of functional exercise capacity. The small increase in distance walked in the second 6MWT in people with ARPD questions whether repeat testing is clinically important in this population. However, functional exercise capacity may be underestimated if a second test is not performed.

Participants demonstrated a greater arterial oxyhaemoglobin desaturation during the 6MWT compared to the ICT, similar to people with COPD, and related to the larger exercising muscle mass utilised during the 6MWT [31]. We have demonstrated a peak cycle test is not required to examine arterial oxyhaemoglobin desaturation in people with ARPD and the 6MWT may provide valuable and unique information on oxygen desaturation during exercise.

The development of ARPD is often characterized by a long latency period from exposure to dust to development of disease [37]. As a result, the mean age of participants was 71 years. With increasing age, the $\mathrm{FEV}_{1} /$ $\mathrm{FVC}$ ratio is known to decrease and the $\mathrm{FEV}_{1} / \mathrm{FVC}$ ratio in our participants was within the range of predicted normal values for people of this age [14].

This study has some limitations. No data were collected on the metabolic and ventilatory responses to the $6 \mathrm{MWT}$ so no direct comparisons can be made for these outcomes with the ICT. People on long term oxygen therapy were excluded so the findings of this study 
cannot be extrapolated to such patients. We did not exclude people if they had a smoking history as this would be unrepresentative of the patient population. Finally, we did not have a group of healthy aged-matched controls upon which a statistical comparison could be made, however data were compared to previously published predicted values for functional and peak exercise capacity.

\section{Conclusions}

This is the first investigation of the effect of ARPD on functional exercise capacity, demonstrating that this population has reduced functional exercise capacity measured by the 6MWT. This study has also established that people with ARPD have reduced HRQoL. Furthermore, we have shown the 6MWD correlated with peak exercise capacity, HRQoL and physical activity. The $6 \mathrm{MWT}$ would be a simple test to perform and integrate into clinical practice to determine functional exercise capacity in people with ARPD and may be a useful surrogate measure of peak exercise capacity and physical activity in the absence of cardiopulmonary exercise testing and activity monitors. With few treatment options available for people with ARPD, research is required to address whether the impairments of reduced exercise capacity and HRQoL are amenable to pulmonary rehabilitation.

\footnotetext{
Abbreviations

ARPD: Asbestos related pleural disease; 6MWT: Six-minute walk test; COPD: Chronic obstructive pulmonary disease; HRQoL: Health-related quality of life; DDB: Dust Diseases Board; CT: Computerised tomography; DLCO: Diffusing capacity for carbon monoxide; ATS: American Thoracic Society; MW: Maximal voluntary ventilation; $\mathrm{FEV}_{1}$ : Forced expiratory volume in one second; FVC: Forced vital capacity; PR: Pulse rate; $\mathrm{SpO}_{2}$ : Oxygen saturation; RPE: Rate of perceived exertion; ICT: Incremental cycle test; $\mathrm{VO}_{2}$ : Oxygen uptake; $\mathrm{VCO}_{2}$ : Carbon dioxide output; SGRQ: St George's Respiratory Questionnaire; MET: Metabolic equivalent; SD: Standard deviation; Cl: Confidence interval; IPF: Idiopathic pulmonary fibrosis.
}

\section{Competing interests}

The authors declare that they have no competing interests.

\section{Authors' contributions}

MD: study design, data collection, data analysis and interpretation, writing of the manuscript. ZM: study design, data collection, data analysis and interpretation, writing of the manuscript. PM: data collection and writing of the manuscript. PC: study design and writing of manuscript, PB: study design and writing of manuscript, JA: study design, data collection, data analysis and interpretation, writing of the manuscript. All authors read and approved the final manuscript.

\section{Support}

Workers' Compensation Dust Diseases Board (DDB) of New South Wales.

\section{Acknowledgements}

The authors would like to thank the Research and Education Unit at the Workers' Compensation Dust Diseases Board (DDB) of New South Wales and the Respiratory Investigation Unit at Royal Prince Alfred Hospital for their assistance with recruitment, and Dr Tiffany Dwyer and Dr Mark Elkins for their assistance with exercise testing and manuscript comments.

\section{Author details}

'Discipline of Physiotherapy (Rm0166) Faculty of Health Sciences, The University of Sydney, 75 East St Lidcombe, Sydney, NSW 2141, Australia. 2Physiotherapy Department, St Vincent's Hospital, Sydney, NSW, Australia. ${ }^{3}$ Department of Respiratory Medicine, Royal Prince Alfred Hospital, Sydney, NSW, Australia. ${ }^{4}$ Sydney Medical School, The University of Sydney, Sydney, NSW, Australia. ${ }^{5}$ Physiotherapy Department, Royal Prince Alfred Hospital, Sydney, NSW, Australia.

Received: 30 August 2012 Accepted: 31 December 2012

Published: 10 January 2013

\section{References}

1. Becklake MR, Bagatin E, Neder JA: Asbestos-related diseases of the lungs and pleura: uses, trends and management over the last century.[erratum appears in Int J Tuberc Lung Dis. 2008 Jul;12(7):824]. Int J Tuberc Lung Dis 2007, 11(4):356-369.

2. Selikoff IJ: The occurrence of pleural calcification among asbestos insulation workers. Ann N Y Acad Sci 1965, 132(1):351-367.

3. McGavin CR, Sheers G: Diffuse pleural thickening in asbestos workers: disability and lung function abnormalities. Thorax 1984, 39(8):604-607.

4. Yates DH, Browne K, Stidolph PN, Neville E: Asbestos-related bilateral diffuse pleural thickening: natural history of radiographic and lung function abnormalities. Am J Respir Crit Care Med 1996, 153(1):301-306.

5. Picado C, Laporta D, Grassino A, Cosio M, Thibodeau M, Becklake MR: Mechanisms affecting exercise performance in subjects with asbestosrelated pleural fibrosis. Lung 1987, 165(1):45-57.

6. Miller A, Bhuptani A, Sloane MF, Brown LK, Teirstein AS: Cardiorespiratory responses to incremental exercise in patients with asbestos-related pleural thickening and normal or slightly abnormal lung function. Chest 1993, 103(4):1045-1050.

7. Shih JF, Wilson JS, Broderick A, Watt JL, Galvin JR, Merchant JA, Schwartz DA: Asbestos-induced pleural fibrosis and impaired exercise physiology. Chest 1994, 105(5):1370-1376.

8. Stevens D, Elpern E, Sharma K, Szidon P, Ankin M, Kesten S: Comparison of hallway and treadmill six-minute walk tests. Am J Respir Crit Care Med 1999, 160(5 Pt 1):1540-1543.

9. Eaton T, Young P, Milne D, Wells AU: Six-minute walk, maximal exercise tests: reproducibility in fibrotic interstitial pneumonia. Am J Respir Crit Care Med 2005, 171(10):1150-1157.

10. Ferrer M, Alonso J, Morera J, Marrades RM, Khalaf A, Aguar MC, Plaza V, Prieto L, Anto JM: Chronic obstructive pulmonary disease stage and health-related quality of life. The quality of life of chronic obstructive pulmonary disease study group. Ann Intern Med 1997, 127(12):1072-1079.

11. Garcia-Aymerich J, Lange P, Benet M, Schnohr P, Anto JM: Regular physical activity reduces hospital admission and mortality in chronic obstructive pulmonary disease: a population based cohort study. Thorax 2006, 61(9):772-778

12. McGlone S, Venn A, Walters EH, Wood-Baker R: Physical activity, spirometry and quality-of-life in chronic obstructive pulmonary disease. COPD: Journal of Chronic Obstructive Pulmonary Disease 2006, 3(2):83-88.

13. Park EK, Hannaford-Turner KM, Hyland RA, Johnson AR, Yates DH: Asbestosrelated occupational lung diseases in NSW, Australia and potential exposure of the general population. Ind Health 2008, 46(6):535-540.

14. Hankinson JL, Odencrantz JR, Fedan KB: Spirometric reference values from a sample of the general U.S. population. Am J Respir Crit Care Med 1999, 159(1):179-187.

15. Quanjer PH, Tammeling GJ, Cotes JE, Pedersen OF, Peslin R, Yernault JC: Lung volumes and forced ventilatory flows. Report working party standardization of lung function tests, european community for steel and coal. Official statement of the european respiratory society. Eur Respir J Suppl 1993, 16:5-40.

16. Crapo RO, Morris AH: Standardized single breath normal values for carbon monoxide diffusing capacity. Am Rev Respir Dis 1981, 123(2):185-189.

17. Campbell SC: A comparison of the maximum voluntary ventilation with the forced expiratory volume in one second: an assessment of subject cooperation. J Occup Med 1982, 24(7):531-533.

18. American Thoracic Society Committee on Proficiency Standards for Clinical Pulmonary Function Laboratories: ATS statement: guidelines for the sixminute walk test. Am J Respir Crit Care Med 2002, 166(1):111-117. 
19. Burdon JG, Juniper EF, Killian KJ, Hargreave FE, Campbell EJ: The perception of breathlessness in asthma. Am Rev Respir Dis 1982, 126(5):825-828.

20. Borg GA: Psychophysical bases of perceived exertion. Med Sci Sports Exerc 1982, 14(5):377-381.

21. Roca J, Whipp BJ: Clinical exercise testing with reference to lung diseases: indications, standardization and interpretation strategies. ERS task force on standardization of clinical exercise testing. European respiratory society. Eur Respir J 1997, 10(11):2662-2689.

22. Jenkins S, Cecins N, Camarri B, Williams C, Thompson P, Eastwood P: Regression equations to predict 6-minute walk distance in middle-aged and elderly adults. Physiother 2009, 25(7):516-522.

23. Jones NL, Makrides L, Hitchcock C, Chypchar T, McCartney N: Normal standards for an incremental progressive cycle ergometer test. Am Rev Respir Dis 1985, 131(5):700-708.

24. Jones PW, Quirk FH, Baveystock CM, Littlejohns P: A self-complete measure of health status for chronic airflow limitation. The St. George's respiratory questionnaire. Am Rev Respir Dis 1992, 145(6):1321-1327.

25. Watz H, Waschki B, Meyer T, Magnussen H: Physical activity in patients with COPD. Eur Respir J 2009, 33(2):262-272.

26. Gosselink R, Troosters T, Decramer M: Peripheral muscle weakness contributes to exercise limitation in COPD. Am J Respir Crit Care Med 1996, 153(3):976-980.

27. Nishiyama O, Taniguchi H, Kondoh Y, Kimura T, Ogawa T, Watanabe F, Arizono S: Quadriceps weakness is related to exercise capacity in idiopathic pulmonary fibrosis. Chest 2005, 127(6):2028-2033.

28. Payton $\mathrm{OD}$, Poland JL: Aging process. Implications for clinical practice. Phys Ther 1983, 63(1):41-48.

29. Chang JA, Curtis JR, Patrick DL, Raghu G: Assessment of health-related quality of life in patients with interstitial lung disease. Chest 1999, 116(5):1175-1182.

30. Spruit MA, Watkins ML, Edwards LD, Vestbo J, Calverley PM, Pinto-Plata V, Celli BR, Tal-Singer R, Wouters EF: Determinants of poor 6-min walking distance in patients with COPD: the ECLIPSE cohort. Respir Med 2010, 104(6):849-857.

31. Luxton N, Alison JA, Wu J, Mackey MG: Relationship between field walking tests and incremental cycle ergometry in COPD. Respirology 2008, 13(6):856-862

32. Hill K, Jenkins SC, Cecins N, Philippe DL, Hillman DR, Eastwood PR: Estimating maximum work rate during incremental cycle ergometry testing from six-minute walk distance in patients with chronic obstructive pulmonary disease. Arch Phys Med Rehabil 2008, 89(9):1782-1787.

33. Cahalin L, Pappagianopoulos P, Prevost S, Wain J, Ginns L: The relationship of the 6-min walk test to maximal oxygen consumption in transplant candidates with end-stage lung disease. Chest 1995, 108(2):452-459.

34. Garcia-Aymerich J, Lange P, Benet M, Schnohr P, Anto JM: Regular physical activity modifies smoking-related lung function decline and reduces risk of chronic obstructive pulmonary disease: a population-based cohort study. Am J Respir Crit Care Med 2007, 175(5):458-463.

35. Thompson PD, Buchner D, Pina IL, Balady GJ, Williams MA, Marcus BH, Berra K, Blair SN, Costa F, Franklin B, et al: Exercise and physical activity in the prevention and treatment of atherosclerotic cardiovascular disease: a statement from the council on clinical cardiology (subcommittee on exercise, rehabilitation, and prevention) and the council on nutrition, physical activity, and metabolism (subcommittee on physical activity). Circulation 2003, 107(24):3109-3116.

36. Sciurba F, Criner GJ, Lee SM, Mohsenifar Z, Shade D, Slivka W, Wise RA: Sixminute walk distance in chronic obstructive pulmonary disease: reproducibility and effect of walking course layout and length. Am J Respir Crit Care Med 2003, 167(11):1522-1527.

37. American Thoracic Society: Diagnosis and initial management of nonmalignant diseases related to asbestos. Am I Respir Crit Care Med 2004, 170(6):691-715.

doi:10.1186/1471-2466-13-1

Cite this article as: Dale et al:. Functional exercise capacity and healthrelated quality of life in people with asbestos related pleural disease: an observational study. BMC Pulmonary Medicine 2013 13:1.

\section{Submit your next manuscript to BioMed Central and take full advantage of:}

- Convenient online submission

- Thorough peer review

- No space constraints or color figure charges

- Immediate publication on acceptance

- Inclusion in PubMed, CAS, Scopus and Google Scholar

- Research which is freely available for redistribution 